\title{
REASSESSMENT OF PAINFUL SHOULDERS AMONG BASEBALL PLAYERS AFTER CONSERVATIVE TREATMENT
}

Alberto Naoki Miyazaki', Marcelo Fregoneze ${ }^{2}$, Pedro Doneux Santos ${ }^{3}$, Luciana Andrade da Silva ${ }^{3}$, Guilherme do Val Sella ${ }^{3}$, Fábio Eduardo Ishioka ${ }^{4}$, João Roberto Polydoro Rosa ${ }^{4}$, José Renato Depari Estelles ${ }^{5}$, Sérgio Luiz Checchia ${ }^{6}$

\section{ABSTRACT}

Objective: The objective of this study was to evaluate the rehabilitation results among baseball players who presented pain and medial rotation deficit in their shoulders. Methods: Out of 55 baseball players assessed between April and June 2009, it was observed that 20 presented pain at some instant during throwing movements. They were advised to undergo a rehabilitation program with exercises to stretch the posterior capsule and reinforce the muscles of the scapular belt, especially the lateral rotators. Eighteen patients followed the advice, while two were lost from the follow-up. The parameters evaluated were: pain, range of motion, strength before the program and strength after the end of the program. Results: Comparing the initial and final assessments, we observed mean increases as follows: $10^{\circ}$ of elevation $(\mathrm{p}=0.001)$; three vertebral levels of medial rotation $(\mathrm{p}<0.001) ; 20^{\circ}$ of medial rotation at $90^{\circ}$ abduction $(p<0.001)$; and $26^{\circ}$ of range of motion $(p<0.001)$. Regarding strength, elevation force increased by $3 \mathrm{kgf}(\mathrm{p}=$ $0.002)$ and lateral rotation force increased by $1 \mathrm{kgf}(\mathrm{p}=0.020)$. Out of the 18 baseball players studied, the pain level improved in 16, while two continued to present pain and underwent magnetic resonance imaging, which showed lesions for surgical treatment. Conclusion: The rehabilitation program conducted among the baseball players was effective and enabled increases in medial rotation, elevation, range of motion and strength of elevation and lateral rotation, consequently producing pain improvements in most of the players.

Keywords - Baseball; Shoulder; Joint Range of Motion

\section{INTRODUCTION}

Baseball players' throwing shoulders are subjected to overloads that may cause anatomical and/or functional alterations. Among these, decreased medial rotation (MR) of the shoulder and increased lateral rotation (LR) are observed ${ }^{(1-7)}$.

The decrease in shoulder MR among these sports players, which occurs because of contraction of the posterior capsule, may have posterointernal and subacromial impacts and may cause muscle imbalance. It has the consequence that lesions appear in the rotator cuff and glenoid labrum, thereby causing pain and functional impotence $\mathrm{e}^{(1,8-11)}$.

Studies have shown that, to prevent and treat these alterations, baseball players should do exercises to stretch the posterior capsule, which leads to a gain in range of motion, particularly regarding $\mathrm{MR}$, and should undergo a strengthening program to rebalance the muscle forces of the scapular belt ${ }^{(7,12-18)}$.

Wilk et $\mathrm{al}^{(7)}$ and Lintner et $\mathrm{al}^{(18)}$ applied a rehabilitation protocol subdivided into four phases, to sports players who performed throwing actions, with the aim

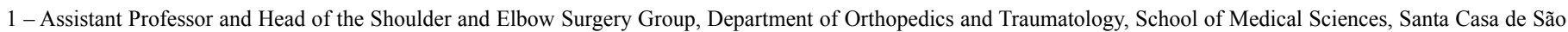
Paulo, São Paulo, SP, Brazil.

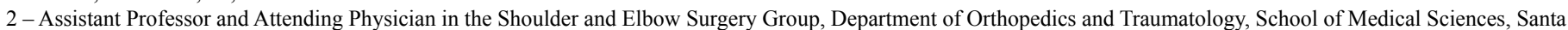
Casa de São Paulo, São Paulo, SP, Brazil.

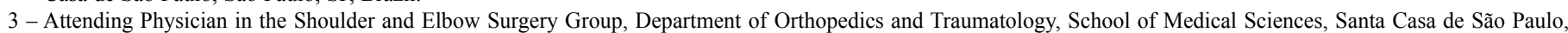
São Paulo, SP, Brazil.

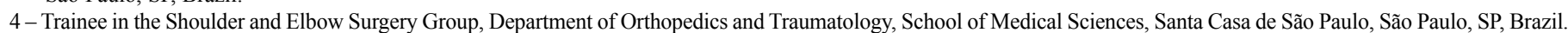

5 - Resident Physician in the Department of Orthopedics and Traumatology, School of Medical Sciences, Santa Casa de São Paulo, São Paulo, SP, Brazil.

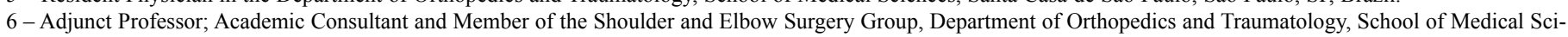
ences, Santa Casa de São Paulo, São Paulo, SP, Brazil.

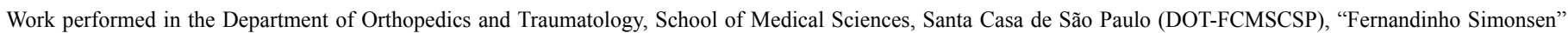
Wing (Director: Prof. Dr. Osmar Avanzi), São Paulo, SP, Brazil.

Correspondence: Rua Dr. Cesário Mota Jr. 112, Vila Buarque, 01221-020 São Paulo, SP. E-mail: ombro@ombro.med.br.

Work received for publication: July 12, 2011; accepted for publication: August 15, 2011.

The authors declare that there was no conflict of interest in conducting this work 
of achieving complete recovery of the shoulder. They also developed other programs aimed at dealing with specific lesions.

Miyazaki et al ${ }^{(19)}$ conducted a study involving baseball players aged 15 years or over, in which they demonstrated statistically significant correlations between pain and altered range of motion; and between length of time practicing the sport and situations of "shoulder at risk". Such situations were described by Burkhart and Morgan ${ }^{(20)}$ as the ratio between the deficit in MR deficit (DMR) and the gain in LR gain (GLR), which shows the imbalance in shoulder adaptations that lead to the appearance of pain and lesions.

The aim of the present study was to assess the rehabilitation results among the baseball players previously studied by Miyazaki et al ${ }^{(19)}$, who presented diminished MR of the dominant shoulder, associated with pain.

\section{MATERIALS AND METHODS}

In the first study, the Shoulder and Elbow Group of the Department of Orthopedics and Traumatology, School of Medical Sciences, Santa Casa de São Paulo, evaluated 55 baseball players between April and June 2009. In that study, it was observed that 20 of them presented pain at some moment during the throwing action. They were advised to undergo a rehabilitation program with exercises to stretch the posterior capsule and reinforce the muscles of the scapular belt (assessment 1) (Figures 1A, 1B, 2A and 2B). Among these 20 players, it was seen that two stopped playing the sport due to personal problems. Thus, these two were excluded from the study, and 18 players participated in the rehabilitation program.

Baseball players aged 15 years or over were included. They needed to have a minimum training frequency of twice a week without any interruptions greater than one month over the preceding six months, along with not presenting any type of lesion diagnosed in the shoulders.

The 18 players who were followed up were male, with a mean age of 21 years (range: 15 to 29 years). Regarding the dominant arm, 17 (94\%) were righthanded and one $(6 \%)$ was left-handed. The mean length of time for which they had been playing baseball was nine years (range: 2 to 23 years), with a mean of three training sessions per week. Among these 18 players, four $(22 \%)$ were pitchers and 14 $(78 \%)$ played in other positions (Table 1).

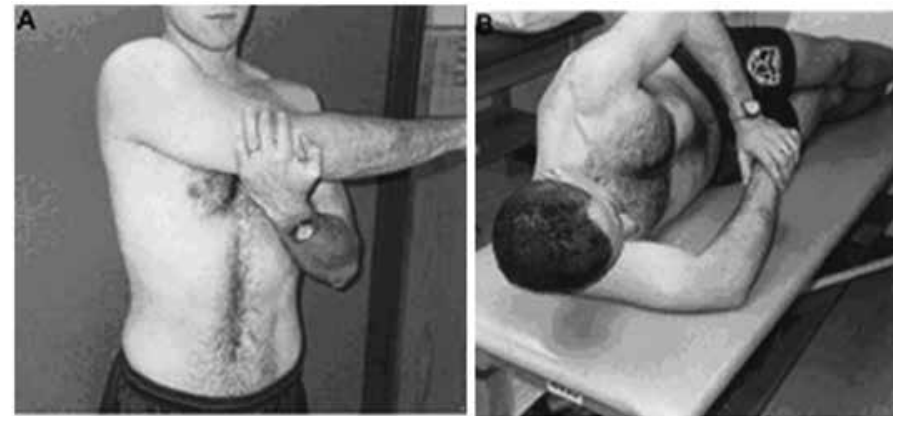

Figure 1 - Baseball player performing stretching of the posterior capsule, standing up (A) and in lateral decubitus (B): twice a day, with five repetitions of 30 seconds each.
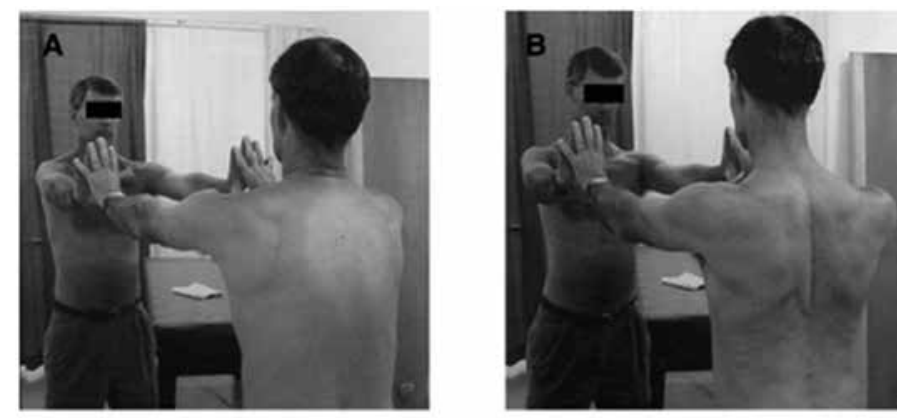

Figure 2 - Baseball player performing one of the strengthening exercises, with protraction $(A)$ and retraction $(B)$ of the scapulas: once a day, with three series of 15 repetitions.

Table 1 - Results relating to pain improvement.

\begin{tabular}{c|c|c|c|c|c}
\hline Patient & Age & Position & $\begin{array}{c}\Delta \mathbf{T} \\
\text { practice } \\
\text { (years) }\end{array}$ & $\begin{array}{c}\text { Pain } \\
\text { improvement } \\
\text { Assessment 2 }\end{array}$ & $\begin{array}{c}\text { Pain } \\
\text { improvement } \\
\text { Assessment 3 }\end{array}$ \\
\hline 1 & 23 & Pitcher & 13 & - & - \\
\hline 2 & 23 & Catcher & 4 & - & + \\
\hline 3 & 20 & Catcher $r$ & 10 & + & + \\
\hline 4 & 15 & Catcher & 9 & + & + \\
\hline 5 & 22 & First base & 11 & + & + \\
\hline 6 & 19 & Shortstop & 14 & + & + \\
\hline 7 & 19 & Pitcher & 12 & - & + \\
\hline 8 & 21 & Pitcher & 10 & + & + \\
\hline 9 & 15 & Fielder & 8 & + & + \\
\hline 10 & 29 & Catcher & 23 & + & + \\
\hline 11 & 20 & Fielder & 14 & + & + \\
\hline 12 & 23 & Shortstop & 5 & + & + \\
\hline 13 & 26 & Fielder & 2 & + & + \\
\hline 14 & 20 & Shortstop & 15 & + & + \\
\hline 15 & 15 & Fielder & 4 & + & + \\
\hline 16 & 22 & Pitcher & 6 & + & + \\
\hline 17 & 21 & Second base & 12 & + & + \\
\hline 18 & 20 & Third base & 2 & + & + \\
\hline
\end{tabular}

Source: Medical archives of Irmandade Santa Casa de Misericórdia de São Paulo. Legend: $\Delta T=$ length of time 
Regarding joint mobility, elevation, LR and MR were evaluated in accordance with the guidance of the American Shoulder and Elbow Surgeons (ASES). Following this, LR and MR were also measured with the patient in a supine position with the shoulder $a b-$ ducted at $90^{\circ}$, the elbow flexed at $90^{\circ}$ and the forearm in neutral rotation, in accordance with the parameters described by Hawkins and Bokos ${ }^{(21)}$ and Donatelli et $\mathrm{al}^{(22)}$ (LR90 and MR90).

All the measurements were made with a graduated goniometer, and the non-dominant shoulder was used as a parameter to calculate possible gains or losses of range of motion, and differences in elevation strength and LR.

The arc of rotation (AR) was calculated by summing the LR90 and MR90 values. The GLR was measured as the difference in LR90 between the dominant and non-dominant shoulders. The DMR was calculated as the different in MR90 between the dominant and non-dominant shoulders. The ratio between the DMR and GLR was calculated to ascertain which baseball players presented a "shoulder at risk", i.e. those for whom the value of this ratio was less than one, as described by Burkhart and Morgan ${ }^{(20)}$.

The isometric contraction force was measured using a manual dynamometer $\left(\mathrm{KERN}^{\circledR} \mathrm{CH} 50 \mathrm{~K} 50\right)$, which was calibrated in accordance with the manufacturer's specifications. The measurements were made in the movement planes recommended by ASES and by Hawkins and Bokos ${ }^{(21)}$ and Donatelli et $\mathrm{al}^{(22)}$.

To prevent compensatory muscle action in the measurements, a vertical resistance force was applied to the arm evaluated, and the joint was kept at an appropriate angle. Three maximum-force measurements were made along each axis evaluated, and the value of the maximum force was noted in kilograms force (kgf), for each of them. The mean for the three repetitions was determined for each axis. The contralateral shoulder was evaluated in the same way.

After nine months of guidance through the rehabilitation program, a new assessment was made on each of the 18 baseball players (assessment 2). They were also asked about their adherence (or non-adherence) to this program, and a check was made on how they were doing the exercises, so that errors in implementing the rehabilitation could be avoided.

From this time onwards, the players were asked every month about their physiotherapy and state of pain. Three months later, the final assessment was made (assessment 3 ).

All the data relating to pain, joint mobility, muscle strength, "shoulder at risk" and rehabilitation were compiled and statistically analyzed using the SPSS software (Statistical Package for the Social Sciences), version 17.0; $p$-values $\leq 0.050(5 \%)$ were taken to be significant. This study was approved by the Ethics Committee for Research on Human Beings of Santa Casa de Misericórdia de São Paulo.

\section{RESULTS}

Nine months after assessment 1 (i.e. at assessment 2 ), we observed that out of the 18 baseball players, 15 had achieved an improvement in their pain. Four players had done the complete rehabilitation program, 13 only did stretching exercises and one did not follow the program.

At the final assessment, one year after assessment 1 (i.e. at assessment 3), only two of the players continued to present pain. Fourteen had been doing all the exercises and four had only been doing the stretching (Table 1).

At assessment 2, it was found that there was a deficit of joint mobility on the dominant side, in relation to the contralateral limb, with increased LR90 ( $p=0.001)$ and deficits in MR $(p=0.001)$ and MR90 ( $p=0.018)$, which were considered to be statistically significant.

At assessment 3, the results were similar to those at assessment 2, but with statistically significant differences in relation to increased LR90 $(\mathrm{p}<0.001)$ and diminished MR ( $\mathrm{p}=0.003)$ and MR90 ( $\mathrm{p}=$ $0.009)$. There was an increase in $\operatorname{AR}(p=0.001)$. All 18 patients showed improvements in mobility and strength (Table 2).

From analysis on muscle strength on the dominant and contralateral sides at assessment 2, statistically significant differences in elevation $(p=0.021)$ and LR90 ( $p=0.031)$ could be seen, with gains in muscle strength in the dominant limb.

Also in relation to muscle strength, in assessment 2 alone there was a statistically significant gain in $\mathrm{LR}$, in comparing the baseball players who had done all the exercises with those who had only done stretching $(\mathrm{p}=0.020)$.

In comparing assessment 3 with assessment 1 in relation to joint mobility, we obtained statistically significant results: regarding mean elevation, there 
Table 2 - Mobility results

\begin{tabular}{|c|c|c|c|c|c|c|c|c|c|c|c|c|c|c|c|c|c|c|c|c|c|c|c|c|c|c|c|}
\hline \multirow{2}{*}{$\mathbf{N}$} & \multicolumn{9}{|c|}{ Assessment 1} & \multicolumn{9}{|c|}{ Assessment 2} & \multicolumn{9}{|c|}{ Assessment 3} \\
\hline & Elev & LR & LR90 ${ }^{\circ}$ & MR & MR90 & AR & GLR & DMR & SR & Elev & LR & $\operatorname{LR}^{\circ} 0^{\circ}$ & MR & $\mathrm{MR}^{\circ} 0^{\circ}$ & AR & GLR & DRM & SR & Elev & LR & $\mathrm{LR}^{\circ} 0^{\circ}$ & MR & MR90 & AR & GLR & DRM & SR \\
\hline 1 & 155 & 70 & 90 & T11 & 50 & 140 & 10 & 30 & + & 160 & 90 & 122 & T8 & 70 & 192 & 32 & 20 & - & 170 & 80 & 125 & T7 & 70 & 195 & 35 & 20 & - \\
\hline 2 & 155 & 80 & 100 & T12 & 80 & 180 & 0 & 10 & $\varnothing$ & 160 & 85 & 120 & T8 & 80 & 200 & 20 & 10 & - & 170 & 80 & 120 & T7 & 90 & 210 & 20 & 0 & - \\
\hline 3 & 170 & 80 & 140 & T7 & 70 & 210 & 5 & 20 & + & 170 & 90 & 120 & T6 & 80 & 200 & 10 & 0 & - & 170 & 80 & 135 & T5 & 90 & 225 & 15 & 0 & - \\
\hline 4 & 140 & 75 & 110 & T10 & 50 & 160 & 20 & 25 & + & 140 & 75 & 110 & T8 & 75 & 185 & 0 & 15 & $\varnothing$ & 170 & 90 & 120 & T6 & 90 & 210 & 10 & 0 & - \\
\hline 5 & 170 & 80 & 110 & T7 & 70 & 180 & -20 & 10 & - & 170 & 90 & 130 & T6 & 90 & 220 & 20 & 0 & - & 170 & 80 & 130 & T5 & 90 & 220 & 20 & 0 & - \\
\hline 6 & 160 & 80 & 120 & T8 & 70 & 190 & -10 & 10 & - & 170 & 90 & 140 & T7 & 90 & 230 & 10 & 0 & - & 170 & 70 & 120 & T6 & 90 & 210 & 30 & 0 & - \\
\hline 7 & 170 & 90 & 120 & T10 & 60 & 180 & 0 & 10 & $\varnothing$ & 170 & 90 & 120 & T7 & 80 & 200 & 0 & 10 & $\varnothing$ & 170 & 90 & 100 & T7 & 90 & 190 & 0 & 0 & $\varnothing$ \\
\hline 8 & 160 & 80 & 130 & T10 & 70 & 200 & 10 & 10 & - & 160 & 90 & 130 & T8 & 70 & 200 & 20 & 10 & - & 170 & 90 & 130 & T8 & 80 & 210 & 40 & 10 & - \\
\hline 9 & 160 & 90 & 130 & T8 & 80 & 210 & 20 & 10 & - & 160 & 90 & 130 & T7 & 70 & 200 & 30 & 5 & - & 170 & 90 & 130 & T6 & 90 & 220 & 40 & 0 & - \\
\hline 10 & 160 & 90 & 100 & T10 & 60 & 160 & -10 & 20 & - & 160 & 80 & 100 & T8 & 70 & 170 & 10 & 15 & + & 160 & 90 & 100 & T7 & 80 & 180 & 10 & 0 & - \\
\hline 11 & 160 & 70 & 120 & $\mathrm{~T} 11$ & 60 & 180 & 0 & 20 & $\varnothing$ & 160 & 80 & 120 & T10 & 60 & 180 & 0 & 20 & $\varnothing$ & 170 & 70 & 100 & T8 & 70 & 170 & 10 & 20 & + \\
\hline 12 & 170 & 90 & 130 & T6 & 50 & 180 & 10 & 30 & + & 160 & 90 & 120 & T5 & 75 & 195 & 10 & 5 & - & 170 & 90 & 125 & T4 & 80 & 205 & 35 & 10 & - \\
\hline 13 & 160 & 90 & 110 & T11 & 70 & 180 & 0 & 10 & $\varnothing$ & 160 & 90 & 100 & T10 & 80 & 180 & 10 & -20 & - & 170 & 90 & 120 & T8 & 90 & 210 & 0 & 10 & $\varnothing$ \\
\hline 14 & 150 & 80 & 120 & T10 & 50 & 170 & -10 & 0 & - & 160 & 75 & 120 & T10 & 60 & 180 & 20 & 0 & - & 170 & 80 & 120 & T8 & 70 & 190 & 20 & 20 & - \\
\hline 15 & 140 & 90 & 100 & $\mathrm{~T} 4$ & 70 & 170 & 10 & 0 & - & 150 & 90 & 120 & T3 & 75 & 195 & 30 & 15 & - & 170 & 90 & 140 & T3 & 80 & 220 & 40 & 10 & - \\
\hline 16 & 155 & 80 & 90 & T7 & 70 & 160 & 0 & 20 & $\varnothing$ & 160 & 70 & 130 & T7 & 80 & 210 & 20 & 10 & - & 170 & 80 & 130 & T6 & 80 & 210 & 40 & 10 & - \\
\hline 17 & 160 & 90 & 140 & T8 & 40 & 180 & 20 & 30 & + & 170 & 90 & 130 & $\mathrm{~T} 7$ & 80 & 210 & 10 & 10 & - & 170 & 90 & 130 & T6 & 90 & 220 & 30 & 0 & - \\
\hline 18 & 160 & 80 & 110 & T7 & 80 & 190 & -10 & 10 & - & 170 & 90 & 120 & T6 & 90 & 210 & 0 & 0 & - & 170 & 90 & 120 & T5 & 90 & 210 & 10 & 0 & - \\
\hline
\end{tabular}

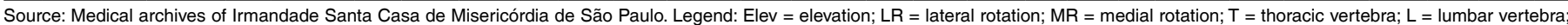
$\mathrm{AR}=$ arc of rotation; $\mathrm{GLR}=$ gain in lateral rotation; $\mathrm{DMR}=$ deficit in medial rotation; $\mathrm{SR}=$ shoulder at risk; $\varnothing=$ impossible to calculate

was an increase of $10^{\circ}(\mathrm{p}=0.001)$; regarding $\mathrm{MR}$, an increase of three vertebral levels $(\mathrm{p}<0.001)$; regarding MR90, an increase of $20^{\circ}(\mathrm{p}<0.001)$; and regarding AR, an increase of $26^{\circ}(\mathrm{p}<0.001)$ (Figures $3 \mathrm{~A}-\mathrm{D}, 4$ and 5).

In relation to muscle strength, an improvement in elevation strength was evident, with an increase of $3 \mathrm{kgf}(\mathrm{p}=0.002)$. There was also an increase in LR strength, of $1 \mathrm{kgf}(\mathrm{p}=0.020)$ (Figure 6) (Table 3).

The relationships of joint mobility, muscle strength and situation of "shoulder at risk" between the baseball players with and without pain did not show statistical correlations in any of the measurement planes at any of the assessments.

\section{DISCUSSION}

Baseball players' shoulders are subjected to extreme forces during the throwing action. Through this, this joint may develop a gain in LR and diminished $\mathrm{MR}^{(18,23)}$. These alterations were also found in the study by Miyazaki et $\mathrm{al}^{(19)}$.

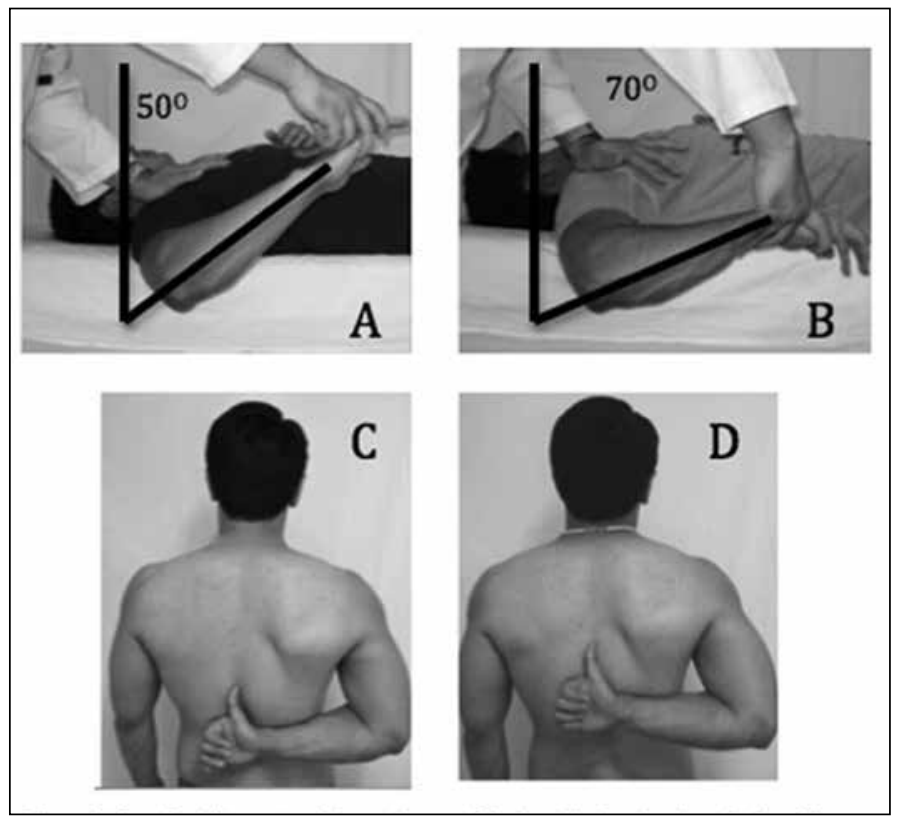

Figure 3 - Case 2: baseball player in supine position with right shoulder abduction of $90^{\circ}$ and elbow flexion of $90^{\circ}$ : (A) with MR90 of $50^{\circ}$ at assessment 1 ; (B) gain of $20^{\circ}$ at assessment 3 ; (C) assessment 1 on the same player, with the limb in shoulder abduction of $20^{\circ}$ and vertebral level T11; (D) gain of four vertebral levels at assessment 3 , reaching vertebral level T7. 


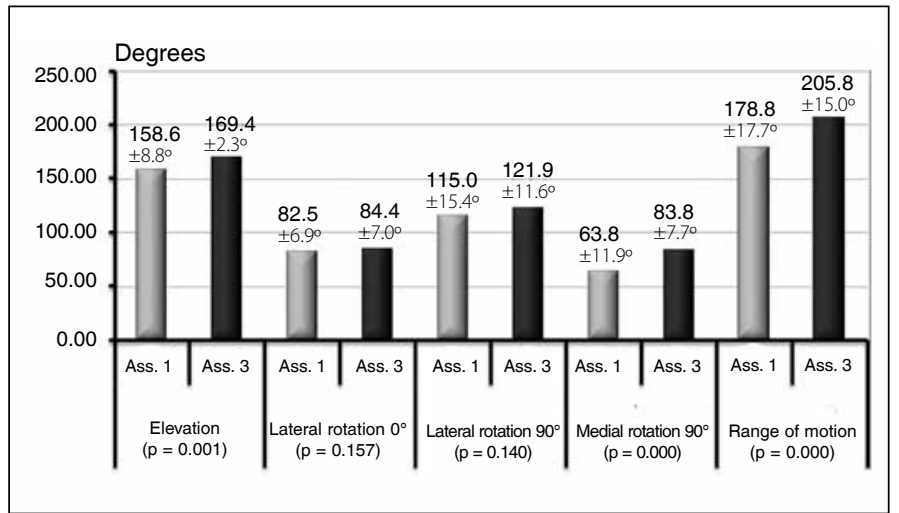

Figure 4 - Comparison of mobility of the affected shoulder between assessments 1 and 3 , in degrees. It was seen that there were statistically significant differences in relation to elevation, AR and MR90.

Source: Medical archives of the hospital. Legend: Ass. $1=$ assessment 1 ; Ass. $3=$ assessment $3 ;{ }^{*}=$ standard deviation.

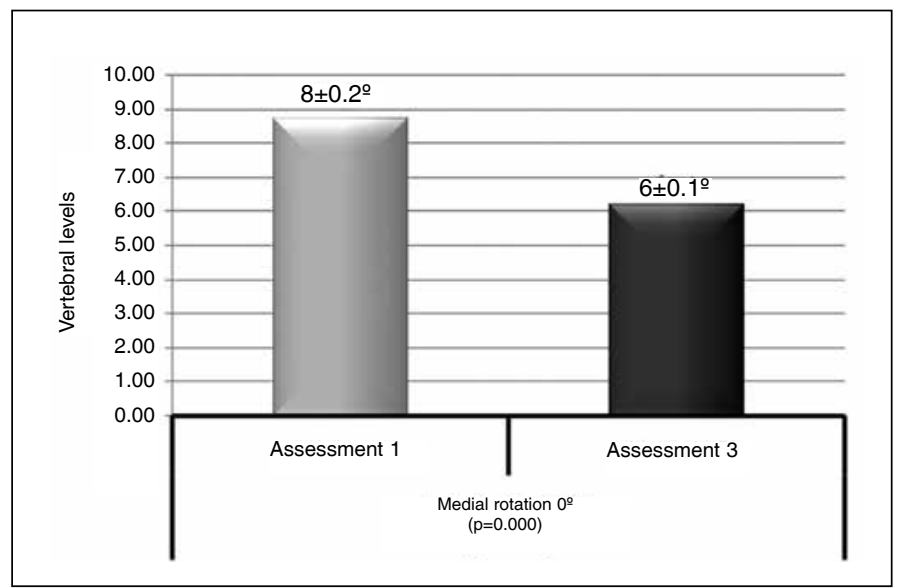

Figure 5 - Comparison of mean mobility of medial rotation (MR) of the affected shoulder between assessments 1 and 3, measured in vertebral levels. A statistically significant difference was seen.

Source: Medical archives of the hospital.Legend: ${ }^{*}=$ standard deviation

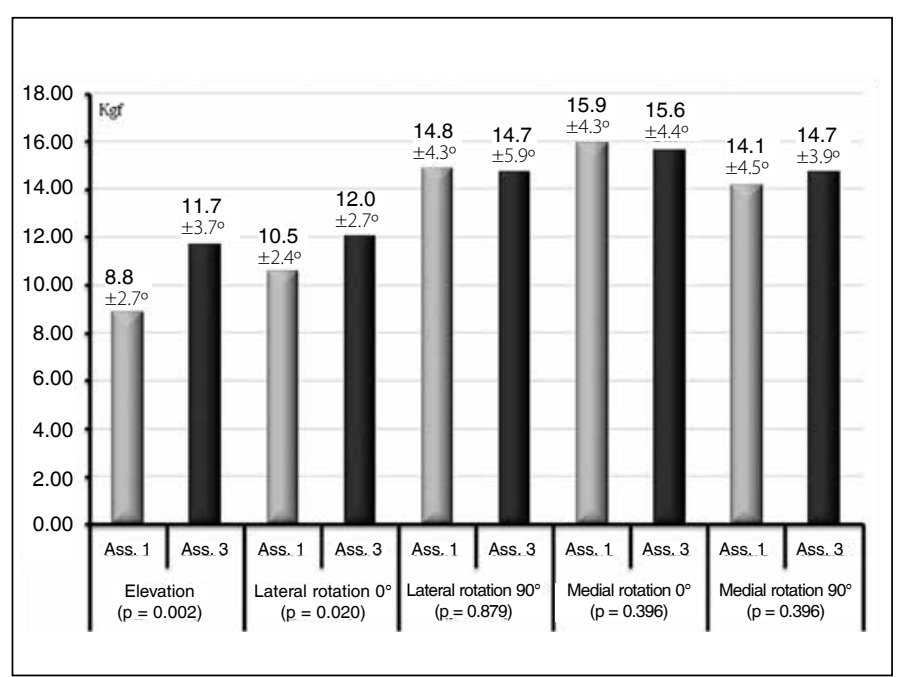

Figure 6-Comparison of the strength of the affected shoulder between assessments 1 and 3 , in kgf. It was seen that there were statistically significant differences in elevation strength and lateral rotation (LR).

Source: Medical archives of the hospital. Legend: Ass. 1 = assessment 1; Ass. $3=$ assessment $3 ;{ }^{*}=$ standard deviation.
According to Burkhart et $\mathrm{al}^{(8)}$, it was observed that shoulder lesions may occur if the AR values are less than $180^{\circ}$ and the MR deficit is greater than $25^{\circ}$. In assessment 1 , we observed that the 18 baseball players with pain during throwing actions had deficits of elevation and MR and a mean $\mathrm{AR}$ of $179^{\circ}$. For this reason, they were referred for physiotherapy, with the aim of recovering their MR.

If contracture of the posture capsule is considered to be the cause of the deficit in MR, and the latter as one of the factors responsible for shoulder lesions, appropriate stretching of the posterior capsule and correction of this deficit should prevent the lesions ${ }^{(1,6,7)}$. Our rehabilitation program led to a significant improvement in pain, probably because we achieved gains in MR, MR90 and AR of $26^{\circ}$ on average, thus reaching $205^{\circ}$. However, despite the improvement in $\mathrm{AR}$, we noted that a difference in AR between the dominant and contralateral arms was maintained, even after the rehabilitation program. We believe that the gain was sufficient to diminish the risk of shoulder lesion, because the players experienced reductions in pain.

Several studies relating to exercise programs for professional baseball players have demonstrated gains in MR and MR90. In some of them, this gain was immediate, after the stretching exercise, but did not last. In others, like the study by Lintner et $\mathrm{al}^{(18)}$, the gain was progressive and became more significant after two years of exercises ${ }^{(13-15,24)}$. Our program showed progressive and long-lasting gains, i.e. the players maintained or increased the gain in movement up to the end of the rehabilitation.

In relation to muscle strength, Wilk et $\mathrm{al}^{(24)} \mathrm{de}-$ monstrated through isokinetic tests that the LR strength of the dominant shoulder of throwers is significantly lower than that of the contralateral shoulder. In compensation, the MR strength is greater in the dominant shoulder than in the contralateral shoulder. They also demonstrated that when the LR muscle strength reached at least $65 \%$ of the MR muscle strength of the same limb, there was a state of balance between the agonist and antagonist muscles of the shoulder. Byram et $\mathrm{al}^{(25)}$ evaluated the LR muscle strength of professional baseball players during the preseason period and noted that those with weakness of the lateral rotators had a greater number of lesions during the season. At assessment 2, we saw that the players 
Table 3 - Strength results in kgf.

\begin{tabular}{|c|c|c|c|c|c|c|c|c|c|c|c|c|c|c|c|}
\hline $\mathbf{N}$ & & & sessmer & & & & & sessmer & & & & & sessme & & \\
\hline & Elev & LR & LR90 $^{\circ}$ & MR & MR90 $^{\circ}$ & Elev & LR & LR90 $^{\circ}$ & MR & MR90 $^{\circ}$ & Elev & LR & LR90 $^{\circ}$ & MR & MR90 \\
\hline 1 & 3.88 & 7.16 & 9.21 & 17.20 & 11.56 & 3.66 & 8.15 & 8.06 & 17.78 & 15.10 & 3.11 & 10.55 & 4.78 & 13.21 & 11.38 \\
\hline 2 & 11.70 & 15.18 & 11.63 & 15.31 & 14.41 & 11.35 & 9.45 & 9.45 & 10.93 & 14.95 & 10.88 & 13.21 & 7.51 & 15.75 & 17.66 \\
\hline 3 & 7.86 & 10.38 & 16.55 & 20.51 & 18.40 & 12.23 & 12.26 & 22.35 & 22.23 & 18.41 & 10.46 & 13.10 & 17.81 & 17.56 & 15.85 \\
\hline 4 & 8.61 & 11.11 & 17.15 & 18.83 & 18.00 & 8.41 & 10.78 & 17.66 & 19.01 & 18.31 & 11.00 & 11.13 & 10.78 & 14.96 & 11.78 \\
\hline 5 & 11.90 & 10.30 & 16.91 & 20.96 & 16.76 & 13.83 & 14.38 & 22.06 & 25.60 & 18.63 & 14.25 & 11.55 & 18.33 & 17.45 & 13.40 \\
\hline 6 & 14.48 & 12.10 & 21.08 & 18.33 & 15.31 & 18.00 & 13.56 & 20.66 & 17.10 & 16.05 & 15.31 & 12.28 & 14.66 & 15.01 & 16.05 \\
\hline 7 & 12.26 & 14.46 & 21.66 & 17.60 & 12.95 & 18.51 & 14.38 & 18.25 & 13.75 & 18.88 & 13.86 & 13.26 & 17.78 & 16.53 & 16.60 \\
\hline 8 & 5.53 & 7.76 & 10.38 & 12.98 & 9.45 & 8.98 & 10.16 & 11.18 & 15.08 & 12.10 & 12.55 & 9.63 & 11.81 & 15.90 & 13.60 \\
\hline 9 & 7.00 & 8.43 & 15.58 & 9.43 & 17.98 & 7.93 & 8.79 & 15.95 & 10.25 & 17.65 & 13.86 & 11.26 & 16.23 & 12.56 & 20.31 \\
\hline 10 & 9.63 & 13.28 & 21.65 & 27.05 & 22.16 & 14.23 & 16.70 & 29.88 & 27.46 & 25.43 & 15.13 & 17.13 & 31.20 & 29.13 & 25.63 \\
\hline 11 & 7.40 & 11.36 & 7.50 & 14.70 & 10.63 & 13.26 & 15.41 & 21.65 & 22.10 & 19.98 & 10.78 & 10.41 & 9.65 & 13.00 & 12.65 \\
\hline 12 & 7.08 & 12.06 & 14.39 & 15.00 & 22.30 & 9.78 & 10.23 & 15.15 & 14.28 & 13.51 & 12.55 & 12.05 & 15.90 & 17.36 & 14.78 \\
\hline 13 & 7.41 & 8.91 & 14.13 & 14.38 & 11.83 & 6.95 & 14.65 & 10.83 & 12.23 & 8.51 & 9.60 & 9.61 & 14.28 & 10.63 & 12.05 \\
\hline 14 & 9.45 & 11.11 & 18.75 & 13.23 & 7.50 & 10.33 & 15.06 & 17.51 & 20.80 & 14.98 & 16.56 & 18.20 & 16.33 & 21.03 & 13.60 \\
\hline 15 & 5.31 & 5.83 & 10.80 & 10.20 & 6.23 & 6.43 & 5.95 & 10.86 & 10.41 & 6.95 & 6.26 & 7.08 & 11.38 & 9.85 & 10.66 \\
\hline 16 & 10.16 & 8.70 & 10.45 & 10.08 & 11.16 & 10.85 & 10.91 & 14.25 & 11.30 & 13.76 & 6.81 & 9.41 & 13.80 & 9.73 & 11.88 \\
\hline 17 & 10.20 & 11.48 & 13.20 & 14.35 & 12.91 & 10.65 & 11.33 & 12.56 & 12.45 & 12.00 & 10.21 & 11.15 & 9.88 & 14.33 & 9.31 \\
\hline 18 & 9.28 & 10.61 & 16.03 & 16.16 & 15.23 & 16.85 & 14.71 & 22.15 & 15.56 & 16.68 & 17.43 & 15.13 & 22.46 & 16.76 & 17.56 \\
\hline
\end{tabular}

Source: Medical archives of Irmandade Santa Casa de Misericórdia de São Paulo. Legend: Elev = elevation; LR = lateral rotation; MR = medial rotation.

had predominantly been doing stretching exercises and not strengthening exercises. We advised our baseball players regarding the importance of doing the entire rehabilitation program. At assessment 3, greater adherence to the exercises was noted, and there were gains in AR, LR and elevation muscle strength.

Our study showed at assessment 1 that the LR strength of the dominant shoulder reached $67 \%$ of the MR strength. However, at assessment 2, we saw that there had been an improvement in the balance between the muscle strengths, with $72 \%$, and at assessment 3 , with $76 \%$. These gains were analyzed and were found to present statistical significance, comparing evaluations 1 and 3, thus showing that the baseball players' shoulders presented an adequate response to the physiotherapy.
Two of the players did not achieve improvements in pain, which led us to investigate the possibility of anatomical injuries developed during sports practice. Burkhart and Morgan ${ }^{(20)}$ also reported that a deficit in MR causes abnormal mobility of the humeral head in the posterosuperior direction, thus resulting in a lesion in the posterosuperior labrum and lesions in the joint portion of the supraspinatus tendon. Magnetic resonance examinations on these two players showed that player no. 7 had a lesion in the posterosuperior labrum, while player no. 1 had a lesion in the posteroinferior labrum. These individuals are undergoing outpatient follow-up, but one of them stopped complaining of pain after stopping his sports activities, and did not wish to continue with the treatment (Figure 7A-C). 

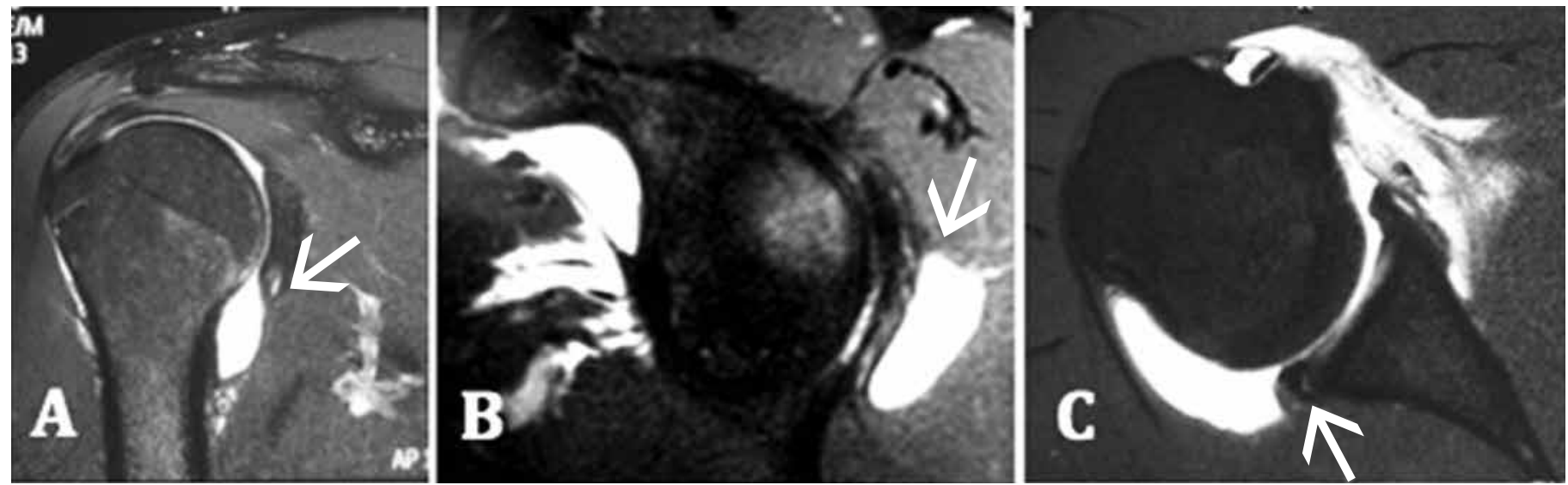

Figure 7 - Case 1: Magnetic arthro-resonance images of the right shoulder of a baseball player who did not achieve improvement of his pain through the rehabilitation program: (A) T2 coronal slice showing lesion of the posteroinferior labrum (arrow); (B) T2 sagittal slice showing posteroinferior paralabral cyst associated with lesion of the posteroinferior labrum (arrow); (C) T2 axial slice showing posteroinferior detachment of labrum (arrow).

\section{CONCLUSION}

The rehabilitation program applied to the baseball players was effective and enabled increases in MR, elevation, AR, elevation muscle strength and LR, with consequent improvement of pain. A mean gain in AR of $26^{\circ}$ was enough to improve the shoulder pain of these baseball players.

\section{REFERENCES}

1. Muraki T, Yamamoto N, Zhao KD, Sperling JW, Steinmann SP, Cofield RH, et al. Effect of posteroinferior capsule tightness on contact pressure and area beneath the coracoacromial arch during pitching motion. Am J Sports Med. 2010;38(3):600-7

2. Bigliani LU, Codd TP, Connor PM, Levine WN, Littlefield MA, Hershon SJ.Shoulder motion and laxity in the professional baseball player. Am J Sports Med. 1997;25(5):609-13.

3. Brown LP, Niehues SL, Harrah A, Yavorsky P, Hirshman HP. Upper extremity range of motion and isokinetic strength of the internal and external shoulder rotators in major league baseball players. Am J Sports Med. 1988;16(6):577-85.

4. Downar JM, Sauers EL. Clinical Measures of Shoulder Mobility in the Professional Baseball Player. J Athl Train. 2005;40(1):23-29.

5. Johnson L. Patterns of shoulder flexibility among college baseball players. J Athl Train. 1992;27(1):44-9.

6. Myers JB, Laudner KG, Pasquale MR, Bradley JP, Lephart SM. Glenohumeral range of motion deficits and posterior shoulder tightness in throwers with pathologic internal impingement. Am J Sports Med. 2006;34(3):385-91.

7. Wilk KE, Meister K, Andrews JR. Current concepts in the rehabilitation of the overhead throwing athlete. Am J Sports Med. 2002;30(1):136-51.

8. Burkhart SS, Morgan CD, Kibler WB. The disabled throwing shoulder: spectrum of pathology Part I: pathoanatomy and biomechanics. Arthroscopy. 2003;19(4):40420.

9. Grossman MG, Tibone JE, McGarry MH, Schneider DJ, Veneziani S, Lee TQ. A cadaveric model of the throwing shoulder: a possible etiology of superior labrum anterior-to-posterior lesions. J Bone Joint Surg Am. 2005;87(4):824-31.

10. Bach HG, Goldberg BA. Posterior capsular contracture of the shoulder. J Am Acad Orthop Surg. 2006;14(5):265-77.

11. Ejnisman B, Andreoli CV, Carrera EF, Abdalla RJ, Cohen M. Lesões músculo-esqueléticas no ombro do atleta: mecanismo de lesão e retorno a prática esportiva. Rev Bras Ortop. 2001;36(10):389-93

12. Sauers E, August A, Snyder A. Fauls stretching routine produces acute gains in throwing shoulder mobility in collegiate baseball players. J Sport Rehabil.2007;16(1):28-40.

13. Goldman B, Sauers EL. The acute effectiveness of PNF stretching and joint mobilizations for increasing posterior shoulder mobility of the professional baseball player. J Athl Train. 2004; 39(Suppl 2):S-56-80.
14. McClure P, Balaicuis J, Heiland D, Broersma ME, Thorndike CK, Wood A. A randomized controlled comparison of stretching procedures for posterior shoulder tightness. J Orthop Sports Phys Ther. 2007;37(3):108-14

15. Decicco PV, Fisher MM. The effects of proprioceptive neuromuscular facilitation stretching on shoulder range of motion in overhand athletes. J Sports Med Phys Fitness. 2005;45(2):183-7.

16. Johansen RL, Callis M, Potts J, Shall LM. A modified internal rotation stretching technique for overhand and throwing athletes. J Orthop Sports Phys Ther. 1995;21(4):216-9.

17. Burkhart SS, Morgan CD, Kibler WB. The disabled throwing shoulder: spectrum of pathology Part III: The SICK scapula, scapular dyskinesis, the kinetic chain, and rehabilitation. Arthroscopy. 2003;19(6):641-61.

18. Lintner D, Mayol M, Uzodinma O, Jones R, Labossiere D. Glenohumeral internal rotation deficits in professional pitchers enrolled in an internal rotation stretching program. Am J Sports Med. 2007;35(4):617-21.

19. Miyazaki AN, Santos PD, Fregoneze M, Silva LA, Sella GV, Checchia SL, et al. Avaliação clínica do ombro doloroso nos jogadores de beisebol. Revis Bras Ortop. 2011;46(2):165-71.

20. Burkhart SS, Morgan CD. The peel-back mechanism: its role in producing and extending posterior type II SLAP lesions and its effect on SLAP repair rehabilitation. Arthroscopy. 1998;14(6):637-40.

21. Hawkins RJ, Bokos DJ. Clinical evaluation of shoulder problems. In: Rockwood CA Jr, Matsen FA 3rd. The Shoulder. 2nd ed. Philadelphia: Saunders; 1998. p. $175-80$

22. Donatelli R, Ellenbecker TS, Ekedahl SR, Wilkes JS, Kocher K, Adam J. Assessment of shoulder strength in professional baseball pitchers. J Orthop Sports Phys Ther. 2000;30(9):544-51.

23. Murachovsky J, Ikemoto RY, Nascimento LGP, Bueno RS, Coelho JA, Komeçu MT, et al. Avaliação da retroversão do úmero em jogadores de handebol. Acta Ortop Bras. 2007;15(5):258-61.

24. Wilk KE, Obma P, Simpson CD, Cain EL, Dugas JR, Andrews JR. Shoulder injuries in the overhead athlete. J Orthop Sports Phys Ther. 2009;39(2):38-54.

25. Byram IR, Bushnell BD, Dugger K, Charron K, Harrell FE Jr, Noonan TJ. Preseason shoulder strength measurements in professional baseball pitchers: identifying players at risk for injury. Am J Sports Med. 2010;38(7):1375-82. 